\title{
Article \\ The Barley Chloroplast Mutator (cpm) Mutant: All Roads Lead to the Msh1 Gene
}

\author{
Franco Lencina *, Alejandra Landau and Alberto R. Prina
}

Citation: Lencina, F.; Landau, A.; Prina, A.R. The Barley Chloroplast Mutator (cpm) Mutant: All Roads Lead to the Msh1 Gene. Int. J. Mol. Sci. 2022, 23, 1814. https:// doi.org/10.3390/ijms23031814

Academic Editors: Jean Molinier and Barbara Hohn

Received: 20 September 2021 Accepted: 19 November 2021 Published: 5 February 2022

Publisher's Note: MDPI stays neutral with regard to jurisdictional claims in published maps and institutional affiliations.

Copyright: (c) 2022 by the authors. Licensee MDPI, Basel, Switzerland. This article is an open access article distributed under the terms and conditions of the Creative Commons Attribution (CC BY) license (https:// creativecommons.org/licenses/by/ $4.0 /)$.
Instituto de Genética "Ewald A. Favret", CICVyA (Centro de Investigación en Ciencias Veterinarias y Agronómicas), INTA (Instituto Nacional de Tecnología Agropecuaria), Dr. Nicolás Repetto y de los Reseros s/n, Hurlingham 1686, Argentina; landau.alejandra@inta.gob.ar (A.L.); prina.albertoraul@inta.gob.ar (A.R.P.)

* Correspondence: lencina.franco@inta.gob.ar; Tel.: +54-11-4621-1684 (ext. 3836)

Abstract: The barley chloroplast mutator $(\mathrm{cpm})$ is a nuclear gene mutant that induces a wide spectrum of cytoplasmically inherited chlorophyll deficiencies. Plastome instability of cpm seedlings was determined by identification of a particular landscape of polymorphisms that suggests failures in a plastome mismatch repair (MMR) protein. In Arabidopsis, $M S H$ genes encode proteins that are in charge of mismatch repair and have anti-recombination activity. In this work, barley homologs of these genes were identified, and their sequences were analyzed in control and cpm mutant seedlings. A substitution, leading to a premature stop codon and a truncated MSH1 protein, was identified in the $M s h 1$ gene of cpm plants. The relationship between this mutation and the presence of chlorophyll deficiencies was established in progenies from crosses and backcrosses. These results strongly suggest that the mutation identified in the Msh 1 gene of the cpm mutant is responsible for the observed plastome instabilities. Interestingly, comparison of mutant phenotypes and molecular changes induced by the barley cpm mutant with those of Arabidopsis MSH1 mutants revealed marked differences.

Keywords: mismatch repair; barley chloroplast mutator; plastome instability; Msh1 gene

\section{Introduction}

Plastids and mitochondria are plant cytoplasmic organelles that are considered semiautonomous in the sense that they only encode part of the proteins they need. Most plastidial and mitochondrial proteins are nuclear-encoded, synthesized in the cytosol and imported with the help of dedicated translocation complexes. Organelle genomes differ from nuclear ones not only in their genetic behavior but also the mechanisms of DNA replication and maintenance [1-4].

With some exceptions, organellar genomes usually behave more conservatively than nuclear genomes in terms of mutation rates [5-10]. For this reason, experimental materials carrying mutations in nuclear genes controlling organelle genome stability are useful tools for expanding the scarce cytoplasmic variability that is available for research and/or plant breeding [11-15].

Several such cases have been detected based on the presence of clonally variegated plants and their breeding behavior in reciprocal crosses [11,16]. One of them is the barley chloroplast mutator ( $\mathrm{cpm}$ ) mutant, which was described as inducing a wide spectrum of cytoplasmically inherited chlorophyll mutants. This is in contrast with several examples in barley, maize and rice inducing a narrow spectrum of maternally inherited chlorophyll mutants, which also differed in showing a faster sorting out [17]. The first evidence of genetic instability in this experimental material was supplied as longitudinal stripes of diverse colors and sizes in plants of the fourth and fifth generation after a seed mutagenic treatment. Afterwards, cytoplasmic inheritance of the chlorophyll deficiencies was determined in subsequent generations of self-pollination, reciprocal crosses and backcrosses. 
Thus, the control of the cytoplasmic instability by a single recessive nuclear mutant was also demonstrated $[17,18]$.

The visual spectrum of mutant phenotypes mostly consisted of clonally variegated plants. Chlorophyll deficiencies were sometimes shown together with morphological changes that mainly consisted of shortened and/or narrower leaves. On the other hand, plants carrying aberrant growth patterns or higher levels of sterility were seldom observed, and none of them proved to be inherited. The chlorophyll deficiencies observed in cpm plants covered a variable proportion of the leaves, from a very narrow clonal stripe in only one leaf to solid or almost solid chlorophyll-deficient mutant plants. Interestingly, some of the latter were viable until maturity, and thus, they could be genetically stabilized by backcrossing them as mother plants with wild-type pollen. In subsequent generations of auto-pollination, it was possible to select families carrying mutant phenotypes only, without any sign of clonal stripes $[18,19]$. These families were called cytoplasmic lines (CLs) and carried a genetically stable mutant plastome expressed in the absence of the cpm allele. In a few CLs, candidate genes were postulated based on phenotypes and sequenced. Mutations were found in the infA $[19,20]$ and the $y c f 3$ gene [21], as well as in the $p s b A$ gene in a family isolated after atrazine treatments [22]. In this way, the first data about the occurrence of point mutations in the plastome of cpm plants were obtained. They consisted of four substitutions and one insertion.

Using a cpTILLING (chloroplast-targeting induced local lesions in genomes) strategy directed to 33 genes and a few intergenic regions [23], a wide spectrum of molecular changes was detected in the plastome of plants belonging to families that carried the cpm genotype through many generations. Numerous polymorphisms, both in genic and intergenic regions, were detected, accounting for at least 61 independent mutational events. Substitutions and small indels (insertions/deletions) in microsatellites constituted the vast majority of the polymorphisms, while increased numbers of recombination events were also observed [23-25]. The activity of the cpm mutator seems to be specific to the chloroplast genome, although its molecular effects on the mitochondrial genome were, so far, not determined.

The variety of cpm-induced polymorphisms was similar to those identified in mutants of the DNA mismatch-repair system (MMR), which is a complex conserved in multiple species, from bacteria to eukaryotes [26]. Most of the MMR proteins are in charge of mismatch recognition [26-29] and possess anti-recombination activity [28-30]. Therefore, mutations in those Msh genes were considered prime candidates for causing the plastome instability observed in cpm plants.

Eukaryotic MutS homolog (MSH) proteins bind DNA molecules with mismatches that have arisen during replication errors. There are seven MSH proteins in plants, which can be grouped in the bacterial MutS1-like and the bacterial MutS2-like subfamilies depending on their lineages and functions [30,31]. MSH1, MSH2, MSH3, MSH6 and MSH7 carry mismatch-recognition domains as proteins belonging to the MutS1 subfamily. They also have an anti-recombination activity between divergent sequences $[26,30,32,33]$. MSH1 forms homodimers, while MSH2 forms heterodimers with MSH3, MSH6 and MSH7. MSH4 and MSH5 proteins belong to the MutS2 subfamily. They form heterodimers that recognize branched DNA structures, such as Holliday junction, are involved in meiotic crossing-over and are lacking mismatch-recognition domains [34,35].

In Arabidopsis, MSH1 has been reported as required for maintaining both, mitochondrial [36-39] and chloroplast DNA stability [2,40], while MSH2, MSH3, MSH6 and MSH7 were found to be required for nuclear genome stability [41-44]. In bacteria, MutS proteins perform their tasks together with two other MMR proteins, the adaptor protein MutL and the endonuclease MutH [29,45]. The same holds true for plant MSH proteins, with the exception of MSH1. The functions of mismatch recognition and endonuclease activity seem to be included in the peculiar domain architecture of MSH1, which is the only MSH protein containing an endonuclease GIY-YIG domain $[31,46]$. Therefore, MSH1 is not expected 
to require proteins homologous to MutL or MutH. This is consistent with the notion that MutL and MutH homologous are not targeted to the organelles [47].

In this investigation, seven Msh homologous genes were identified, five of which were sequenced in cpm and control seedlings. A substitution introducing a premature stop codon in exon 17 of the cpm Msh1 gene was found. In addition, the relationship between the Msh 1 mutant allele and the mutator phenotype was able to be established in progenies from crosses and backcrosses.

Taken together, these results suggest that the $M s h 1$ gene mutant is a strong candidate to be responsible for the chloroplast genomic instability induced in cpm plants.

\section{Results}

\subsection{Identification and Amplification of the Coding Sequences of Barley Msh Genes}

Searching for the orthologs of the Arabidopsis thaliana MSH genes in barley, six loci with functional annotation were identified: Msh1 (HORVU2Hr1G087660), Msh2 (HORVU1Hr1G030930), Msh3 (HORVU2Hr1G085940), Msh4 (HORVU2Hr1G031870), Msh5 (HORVU1Hr1G066830) and Msh6 (HORVU5HrG1061020). The barley Msh7 gene could not be identified; however, the $M s h 7$ gene of another cereal (Triticum turgidum) was found, and its amino-acidic sequence was used to perform a tblastn against the Hordeum vulgare genome. Several hits with different lengths of alignments were obtained for one locus of barley (HORVU3Hr1G021520). In this way, this locus was named as barley Msh7 gene because it was understood that it did not have a functional annotation.

The identity of each one of the Msh loci in barley was searched for by alignments of the proteins encoded by these genes with the MSH proteins of $A$. thaliana, where the identity positions were higher than 50\% (60.5\% for MSH1, 64.8\% for MSH2, 53\% for MSH3 considering only the last part of the $A$. thaliana protein, $73.2 \%$ for MSH4, $60.1 \%$ for MSH5, 53.6\% for MSH6 considering only the last part of the $A$. thaliana protein), with the exception of MSH7, where this value was $42.6 \%$. Moreover, similar structural annotations to A. thaliana genes for each of the barley Msh genes could be observed. In this way, the most probable structural annotation was determined. The gene structures are shown in Figure 1. Briefly, they corresponded to splicing variants producing some of the isoforms predicted in the database Ensembl Plants for MSH1, MSH2, MSH3 and MSH4, and it was a combination of exons belonging to different predicted isoforms for MSH5, MSH6 and MSH7 (See Table S1). Moreover, in comparison with the A. thaliana proteins, barley MSH3 and MSH6 lacked the first part of the protein, and MSH7 had an extra part at the beginning of the protein not present in A. thaliana MSH7.

The sizes of the genes ranged from $5.73 \mathrm{~Kb}$ for $\mathrm{Msh} 3$ to $33.59 \mathrm{~Kb}$ for $\mathrm{Msh} 5$ (see Figure 1). Because of these large sizes, it was decided to amplify the coding sequences (CDS) of these genes in barley. The overlapping amplicons designed to cover the complete CDS are listed in Table S1. Amplicons of the estimated sizes were obtained using RT-PCR of all analyzed genes in both cpm and control genotypes. This indicates that these genes were expressed in the embryos from which the RNA samples were isolated and also that the structural annotations used for primer design were correct.

Using TargetP software, signal peptides to organelles were identified. With version 1.1, a dual location to mitochondria and chloroplasts was predicted for MSH1. MSH5 and MSH7 had a predicted location in mitochondria only, although with a low confidence value. However, with version 2.0, only the dual organelle localization of the MSH1 protein was confirmed (Table S2A and Table S2B, respectively). 


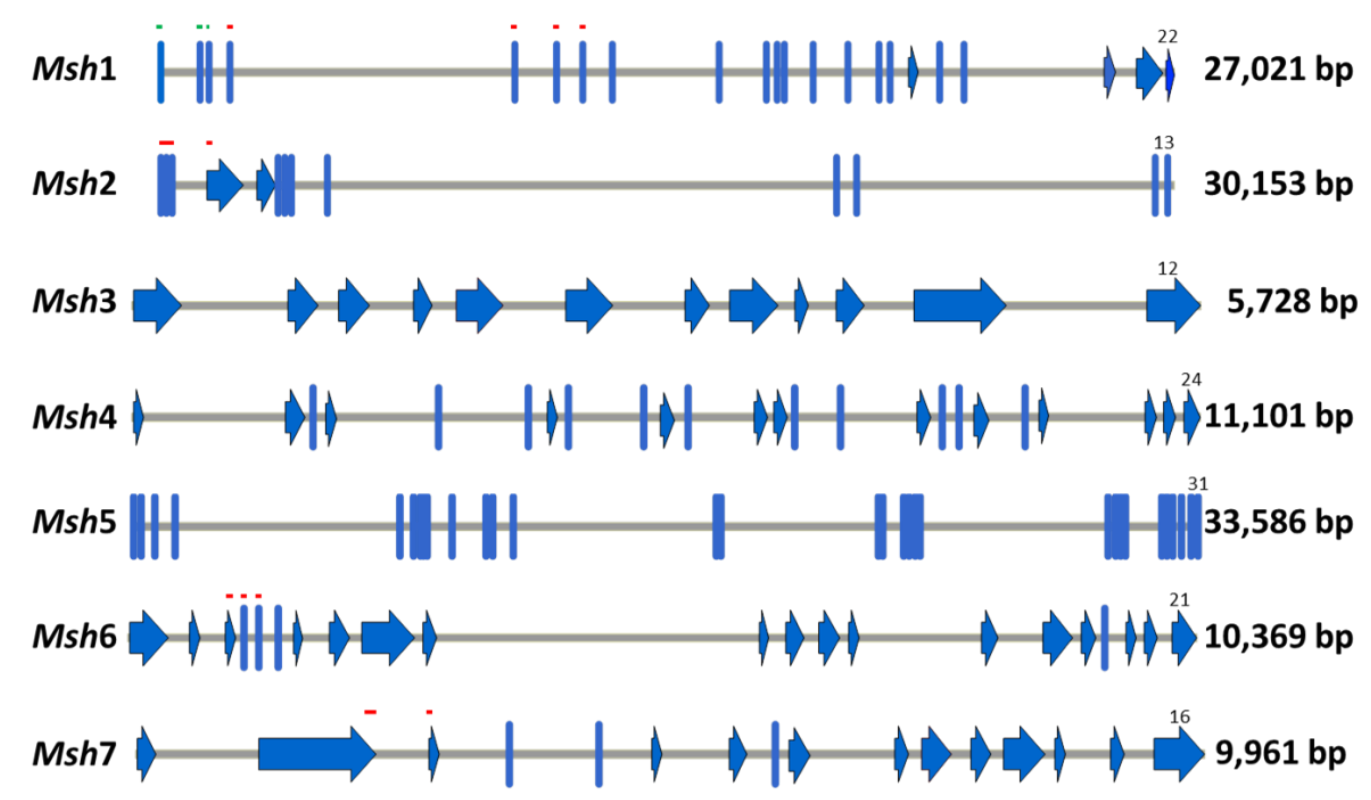

Figure 1. Structural annotation of barley Msh genes. The structure was determined by alignment of its encoded proteins with the $A$. thaliana proteins and corroborated by sequencing of cDNAs covering the CDS in Msh1, Msh2, Msh3, Msh6 and Msh7. Blue lines and arrows represent exons, and grey lines represent introns. The DNA regions encoding the mismatch-recognition domains are indicated by red lines, and the dual-organelle signal peptide by green lines. The region encoding the Msh3 mismatch-recognition domain is not shown because it is located in the missing part of this gene in comparison to the A. thaliana gene. Msh4 and Msh5 do not have regions encoding mismatch-recognition domains. The gene sizes and the number of exons are indicated on the right.

\subsection{Sequencing and Detection of a Premature Stop-Codon Mutation in the Cpm Msh1 Gene}

Comparison of the amplicon sequences covering the CDS of five Msh genes of cpm and the control genotype with the reference sequence (Ensembl Plants Hordeum vulgare IBSC_v2 release-51) confirmed the correct structural annotation used in the primer design for sequencing. Msh4 and Msh5 were not sequenced because they do not have a mismatchrecognition domain. The cpm sequences only differed from that of the control in a single polymorphism, while cpm and control presented several polymorphisms with respect to the reference sequence. The sequences of the Msh2 and Msh3 genes of control and cpm were identical to that of the reference. On the other hand, 16 substitutions were identified in the Msh 1 gene, five in the Msh6 and seven in the Msh7 genes of cpm and control, with respect to the reference. Thirteen of these substitutions would change the amino-acid sequence in the encoded protein, and one of these changes was only found in the cpm genotype (see Table 1). As mentioned above, the cpm sequence only differed from that of the control in a single polymorphism; it was a G1806A substitution in the Msh1 gene that generates a premature stop codon in exon 17. This mutation would produce a truncated protein of half the size of the wild-type version, which would lose the DNA binding and the ATPase domains (Figure 2). Alignment of MSH1 proteins from the reference, cpm mutant and the control genotype is shown in Figure S1. The Msh CDS sequences of the analyzed genes in cpm and the control were deposited in the Genbank database (see Data Availability Statement). 
Table 1. Polymorphisms identified in Msh genes of cpm and control genotypes in comparison with the reference sequence (Ensembl Plants Hordeum vulgare IBSC_v2 release-51). In Msh2 and Msh3, no changes were found. Msh4 y Msh5 were not sequenced because they do not have a mismatchrecognition domain.

\begin{tabular}{|c|c|c|c|c|}
\hline Gene & Nucleotide Change $^{\text {a }}$ & Exon Location & $\begin{array}{c}\text { Amino-Acid } \\
\text { Change }\end{array}$ & Genotype \\
\hline \multirow{16}{*}{ Msh1 } & A216G & 2 & - & cpm and control \\
\hline & $\mathrm{T} 225 \mathrm{C}$ & 2 & - & cpm and control \\
\hline & A263C & 3 & Q88P & cpm and control \\
\hline & A300G & 3 & - & cpm and control \\
\hline & T696C & 8 & - & cpm and control \\
\hline & T831C & 9 & - & cpm and control \\
\hline & G1806A & 17 & W602* & $\mathrm{cpm}$ \\
\hline & T2060C & 18 & M687T & cpm and control \\
\hline & G2799A & 21 & - & cpm and control \\
\hline & G2861A & 21 & R954Q & cpm and control \\
\hline & $\mathrm{C} 2988 \mathrm{~T}$ & 21 & - & cpm and control \\
\hline & G3000A & 21 & - & cpm and control \\
\hline & G3046A & 21 & V1016I & cpm and control \\
\hline & G3135T & 21 & - & $\mathrm{cpm}$ and control \\
\hline & C3226T & 22 & - & cpm and control \\
\hline & A3235G & 22 & M1079V & cpm and control \\
\hline \multirow{5}{*}{ Msh6 } & G498A & 3 & - & cpm and control \\
\hline & $\mathrm{T} 1144 \mathrm{C}$ & 9 & - & cpm and control \\
\hline & $\mathrm{T} 1577 \mathrm{C}$ & 10 & L526S & cpm and control \\
\hline & A2340G & 15 & - & cpm and control \\
\hline & G2464A & 16 & V822I & cpm and control \\
\hline \multirow{7}{*}{ Msh7 } & C337T & 2 & P113S & cpm and control \\
\hline & $\mathrm{T} 440 \mathrm{C}$ & 2 & V147A & cpm and control \\
\hline & $\mathrm{T} 1739 \mathrm{C}$ & 7 & F580S & cpm and control \\
\hline & G1860T & 9 & M620I & cpm and control \\
\hline & A3030G & 14 & - & cpm and control \\
\hline & $\mathrm{C} 3171 \mathrm{~T}$ & 15 & - & cpm and control \\
\hline & G3317A & 16 & R1106K & cpm and control \\
\hline
\end{tabular}

a coordinate refers to the coding sequence (CDS). ${ }^{*}$ indicates stop codon.

\subsection{Analysis of the Msh1 DNA Region Carrying the Premature Stop Codon in Cpm and CLs Seedlings}

In order to confirm the presence of the premature stop-codon mutation identified in the CDS of the cpm Msh1 gene, DNA samples were isolated from five different cpm seedlings and five of the control. After sequencing a $655 \mathrm{bp}$ amplicon comprising exon 16, intron 16 and exon 17, the existence of the premature stop-codon mutation was confirmed only in cpm seedlings (see electropherograms in Figure 2).

With the purpose of confirming the relationship between the premature stop-codon mutation in the Msh 1 gene and the plastome instability that produces chlorophyll deficiencies in cpm seedlings, seven CLs were analyzed. As explained in Materials and Methods, CLs are homoplastomic, each carrying only one particular mutant plastome that gives a determined chlorophyll-deficient type. They did not show any clonal longitudinal stripe with different chlorophyll pigmentation that would indicate they were genetically unstable. In accordance with this, by sequencing the $655 \mathrm{bp}$ amplicon covering exons 16 and 17 of the Msh 1 gene in seven CLs, it was determined that none of them had the Msh1 mutation. In addition, one of those CLs (CL4) was characterized as showing a high rate of phenotypic reversions in segregating progenies from backcrosses of CL4 plants as females with cpm pollen [18]. The phenotypic reversions were easily observed as the appearance of darker green stripes on a CL4 virescent background (Figure 3), and this was used to easily identify seedlings that recovered plastome instability as early as in the $F_{2}$ generation. In two families derived from seedlings showing phenotypic reversions, it was observed that they 
carried the stop-codon mutation in the $M s h 1$ gene. A diagram showing the handling of the material to investigate phenotypic reversions in another CL (CL2) can be seen in a previous paper [19].

A

B
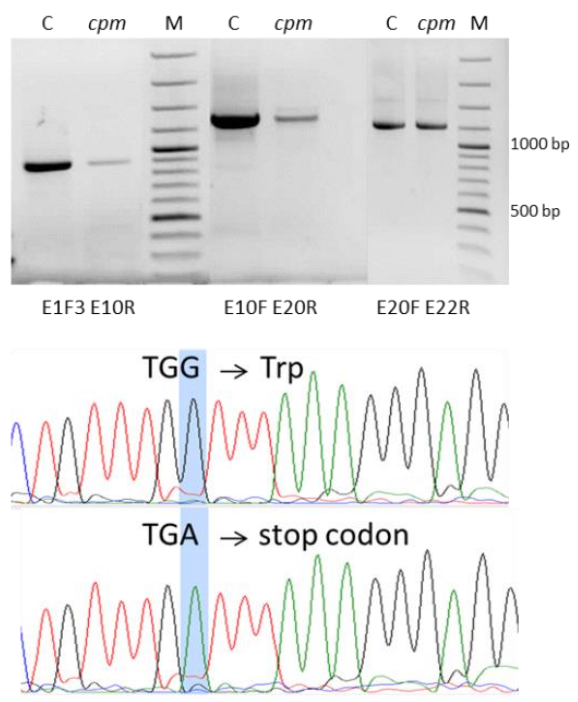

C

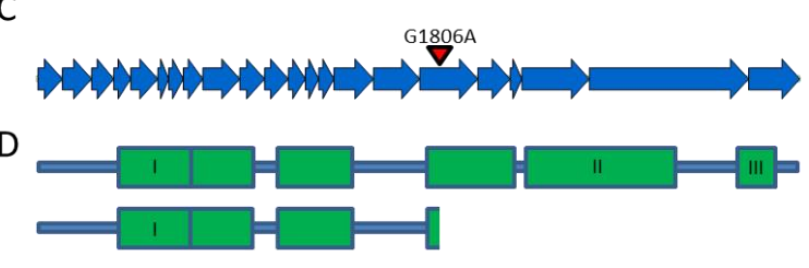

Figure 2. Amplification and sequencing of $M s h 1$ gene from cpm and control genotypes. (A) Amplicons covering the CDS of the Msh1 gene obtained by RT-PCR from embryo RNA. C: control, cpm: barley chloroplast mutator, M: molecular marker. E1F3E10R, E10FE20R and E20FE22R represent the three CDS amplicons sequenced in the Msh1 gene (see Supplementary Materials). (B) Electropherograms showing the stop-codon mutation G1806A in cpm. (C) Location of the substitution G1806A in exon 17 of the Msh1 gene in cpm. (D) Domains of the MSH1 protein in the control (upper) and cpm (lower) genotypes. I and II represent the most characteristic domains of MSH proteins. I is the DNA binding domain, II is the ATPase domain and III is the endonuclease GIY-YIG domain (only present in the MSH1 protein).

A

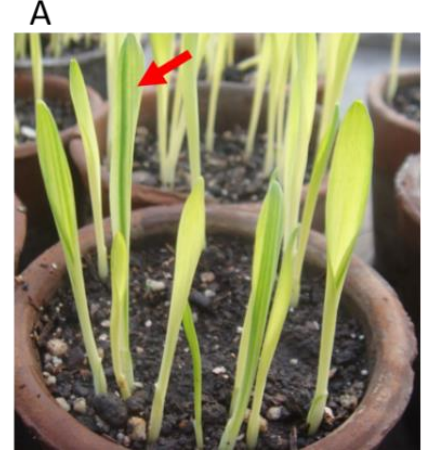

B

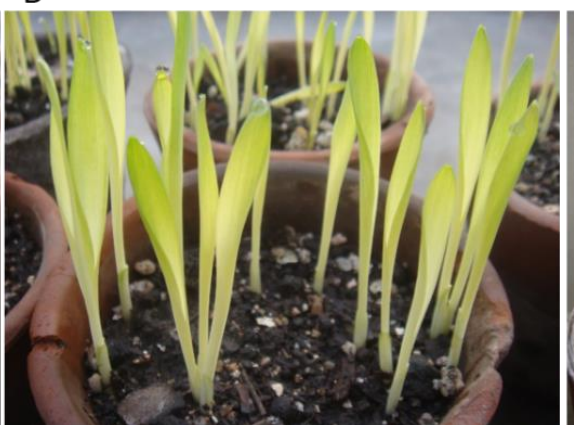

C

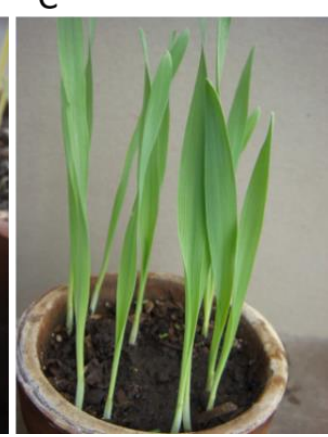

Figure 3. Progenies of CL4 plants carrying cpm mutator- or Cpm wild-type nuclear genotypes. (A) Segregation of solid virescent seedlings or clonally variegated ones (red arrow). Variegated seedlings ( $\mathrm{cpm}$ genotype) show darker green stripes of different sizes on a virescent background, which supposedly originated in the slow and unleashed sorting out of plastome mutants in comparison with the segregation of nuclear ones, which are expected to segregate as solid mutants since the F2 generation. (B) Seedlings showing a solid mutant virescent phenotype (Cpm genotype). (C) Control wild-type seedlings. 


\subsection{Prediction of Alternative Subcellular Locations of MSH1 Protein in Barley}

Analysis of the barley Msh 1 gene $5^{\prime}$ UTR sequence showed the presence of the atypical translation initiation codon CTG, apart from the typical ATG codon (Figure 4A).

A

MQRLLASSIVAATPRWLPLANSILRR

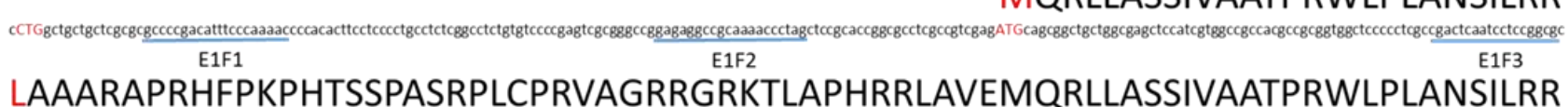

B

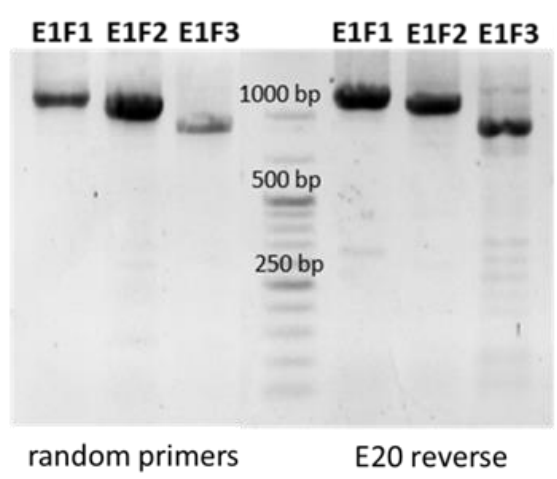

Figure 4. Alternative start codons of the Msh 1 gene in barley. (A) Typical (ATG), alternative and atypical start codon (CTG) on the 5'UTR sequence of the barley Msh 1 gene are shown in red, along with, the beginning of the MSH1 protein with dual organelle (upper) or chloroplast-only targeting (lower). The positions of three different forward primers (E1F1, E1F2 and E1F3) are indicated by blue lines. (B) Amplification of the $5^{\prime} \mathrm{UTR}$ of barley Msh 1 transcripts. Three forward primers were used: E1F1 and E1F2, located in the 5'UTR, and E1F3, located downstream of the typical ATG start codon. Control cDNA was obtained using both random primers and E20 reverse primer. Amplicons E1F1-E11R (1196 bp) and E1F2-E11R (1124 bp) were observed, as well as E1F3-E10R (924 bp).

To study the existence of mRNA containing the 5'UTR with the atypical start codon, the amplification of this region in the Msh 1 gene of the control barley was made using forward primers located in three different positions of the gene. E1F1 and E1F2 were located upstream of the typical ATG start codon, and the E1F3 primer was located downstream of the ATG start codon. Amplifications were obtained with all the forward primers, which indicates the presence of the $5^{\prime} \mathrm{UTR}$ in transcripts of the $M$ sh 1 gene of barley (Figure $4 \mathrm{~B}$ ).

According to TargetP-1.1, the prediction of the subcellular location of the protein is different, depending on the initiation codon used (Table 2). A dual mitochondrial/chloroplast location was predicted for a protein synthesized from the initiation codon ATG, while only a chloroplast location was predicted if the barley MSH1 protein was translated from the CTG codon.

Table 2. Prediction of the subcellular locations of barley MSH1 protein versions according to TargetP1.1 software, Technical University of Denmark, Lyngby, Denmark. The location with the highest score is the most likely one according to TargetP.

\begin{tabular}{cccccc}
\hline Protein & $\begin{array}{c}\text { Mitochondrial } \\
\text { Transfer } \\
\text { Peptide }\end{array}$ & $\begin{array}{c}\text { Chloroplast } \\
\text { Transfer } \\
\text { Peptide }\end{array}$ & $\begin{array}{c}\text { Signal Peptide } \\
\text { to Secretory } \\
\text { Pathway }\end{array}$ & $\begin{array}{c}\text { Any Other } \\
\text { Location }\end{array}$ & Location \\
\hline $\begin{array}{c}\text { MSH1 } \\
\text { typical start } \\
\text { codon }\end{array}$ & 0.791 & 0.620 & 0.004 & 0.006 & $\begin{array}{c}\text { Mitochondria } \\
\text { Chloroplast }\end{array}$ \\
\hline $\begin{array}{c}\text { MSH1 } \\
\text { alternative } \\
\text { start codon }\end{array}$ & 0.279 & 0.754 & 0 & 0.098 & Chloroplast \\
\hline
\end{tabular}




\section{Discussion}

\subsection{A Mutation in the Msh1 Gene as Candidate for the Barley cpm}

The diverse plastome polymorphisms previously observed in barley cpm plants exhibited a landscape of molecular changes typical of a missing DNA repair system dedicated to function in the chloroplasts [16,23-25]. In this communication, the efforts to identify the repair system, the mutation of which led to the chloroplast mutator $\mathrm{cpm}$, are described. Genes coding for mismatch-repair enzymes were identified based in their homology to Arabidopsis genes. Seven genes were identified, and five of them were sequenced; Msh3 and Msh4 genes were not sequenced since they lack the mismatch-recognition domains. Target-P prediction of subcellular location of barley MSH proteins showed that MSH1 would be the only one with a chloroplast/mitochondrial dual-targeting peptide. Like the Arabidopsis homolog, the Msh 1 gene of barley consists of 22 exons and is of similar size [36].

The sequence of the Msh 1 gene of the cpm plants exhibited a G1806A mutation in exon 17, leading to a predicted translational stop. This mutation was the only difference found between all sequenced cpm and wild-type control Msh genes. The premature stop codon would result in a truncated MSH1 protein of half the size of the normal version, which would drastically affect the function of the protein due to the loss of the ATPase and the endonuclease domains. Importantly, in seven CLs carrying a genetically stable plastome (see Materials and Methods), the stop-codon mutation was absent. Thus, the stable mutant chloroplast genotype is independent of the mutated mismatch-repair system. On the other hand, the G1806A mutation was present in plants that recovered the phenotypic instability in the $F_{2}$ and further segregating generations resulting from backcrossing plants of the highly reverting Cytoplasmic Line 4 (CL4) with cpm pollen [18]. These results strongly support the hypothesis that the stop-codon mutation in the Msh 1 gene is responsible for the high frequency and the wide spectrum of chlorophyll-deficient types, as well as for the numerous and varied plastome molecular changes observed in cpm plants.

\subsection{Barley and Arabidopsis Mutants Exhibit Different Phenotypes}

The most commonly reported phenotypes of the Arabidopsis chloroplast mutator ( $\mathrm{chm}$ ) mutants were conspicuous white, yellow-green variegation and distorted leaves associated with high levels of sterility $[48,49]$. These mutant plants exhibited new restriction fragments in the mitochondrial genome due to DNA rearragments [49,50]. The Chm gene, renamed AtMSH1, was shown to encode a protein related to the E. coli MutS gene and the yeast mitochondrial MSH1 gene [36]. The AtMSH1 gene controls substoichiometric shifting, which involves rapid and dramatic changes in relative copy number of portions of the mitochondrial genome over the timespan of one generation. Subgenomic DNA molecules often contain recombination-derived chimeric sequences, and the genomic shifting can alter plant phenotype because the process activates or silences mitochondrial sequences located on the shifted molecule [36]. Mutations in either the ATPase or the endonuclease domains were observed to trigger the mitochondrial substoichiometric shifting, as well as the variegated phenotype [46].

While no plastome polymorphisms were found during the first investigations in the Atmsh 1 mutants [49], a low frequency of plastome recombination events was later observed [51]. Lack of AtMSH1 protein led to a massive increase in the frequency of point mutations and small indels in mitochondrial and the plastid DNA, as was recently shown [2]. Depending on which of the two start codons is used, an AtMSH1 protein translated from a typical ATG codon preferentially targets mitochondria while a protein translated from an atypical start codon exhibits dual targeting [52].

The differential targeting to the organelles, depending on the species, could explain the differences between the cpm barley and the Arabidopsis mutants $[46,47,52]$. In this regard, it is interesting to realize that an alternative start codon could be identified in the barley MSH1 protein. Morever, the presence of transcripts covering the $5^{\prime} \mathrm{UTR}$, in which the sequence of the alternative start codon is located, was shown by RT-PCR. TargetP predicts a chloroplast location for the protein translated from the alternative codon. Therefore, 
the Arabidopsis protein could be mainly involved in mitochondrial DNA stability and the barley homolog in maintaining chloroplast DNA stability. This hypothesis requires further investigation to assess the possible influence of the barley MSH1 protein on the mitochondrial genome.

In the cpm mutant, variegation was not associated with high levels of sterility shown for Arabidopsis $m s h 1$ mutants [49]. Additionally, effects of developmental reprogramming due to depletion of the Arabidopsis MSH1 protein [53] were not observed in cpm plants $[17,18,23]$. This was observed in several plant species and was related to epigenetic modifications in nuclear genes [54-59].

Another reason for the differences observed between the mutants in Arabidopsis and barley could be based on the different kinds of mutations these plants carry. Arabidopsis knockout mutants [2,36,51] or the RNAi mutants obtained in multiple species [51] may have more drastic consequences than those of the premature stop-codon mutation identified in cpm plants. In this context, it should be considered that the barley mutant is expected to retain the mismatch-recognition function of the MSH1 protein. Similarly, an Arabidopsis mutant carrying a T-DNA insertion in the eighth intron of the MSH1 gene could also reduce but not eliminate its function, resulting in weaker phenotypic effects and lower mutation rates than those induced by the knockouts [2].

\section{Materials and Methods}

\subsection{Plant Material}

Plant material consisted of embryos and seedlings of a two-row cultivated barley (H. vulgare) genotype, homozygous for the barley chloroplast mutator (cpm) gene, using as control its parental line from which it was isolated after mutagenic treatments [17]. Besides, plant material included seedlings belonging to seven cytoplasmic lines (CLs): CL1, CL2, CL3, CL4, CL5, CL7C and CL13. Each CL has one particular chlorophyll mutant phenotype that was induced by the $\mathrm{cpm}$. The CLs were obtained after crossing cpm chlorophyll-deficient plants as females with control plants and later selecting among the segregating families those not showing new stripes of different colors than that of the mutant background. For this reason, they are considered to be carrying a genetically stable cytoplasm. Obtainment of the CLs and description of the phenotypes of some of the CLs were already reported $[16,18-21,60]$. One of them, CL4, is characterized by a virescent phenotype (yellowish young leaves that gradually turn to normal or almost normal green at maturity), which shows a high rate of phenotypic reversions in segregating progenies coming from backcrosses of CL4 as female with cpm pollen [18]. This CL4 peculiarity was used to identify seedlings that recovered the plastome instability as early as in the $\mathrm{F}_{2}$ generation.

Embryos of cpm and the control genotype were used for RNA isolation after $48 \mathrm{~h}$ of germination in Petri dishes. DNA samples were extracted from the second leaf of cpm, control and CLs seedlings grown in pots under glasshouse conditions.

\subsection{Identification of Msh Genes of Barley}

The reference sequences of $M$ sh genes were obtained from the $H$. vulgare database of Ensembl Plants (https:/ / plants.ensembl.org/index.html (accessed on 19 June 2021)) as orthologous of MSH genes of $A$. thaliana. The most probable structural annotation (exons, introns and CDS sequences) of barley Msh genes was determined by alignment of the protein sequences between $A$. thaliana and all the possible isoforms of barley MSH proteins. Besides, predictions for their subcellular location for each of the MSH barley proteins were obtained by identification of N-terminal signal peptides using TargetP-1.1 and -2.0 versions (Technical University of Denmark, Lyngby, Denmark; http:/ / www.cbs.dtu.dk/services / TargetP / (accessed on 09 July 2021)).

\subsection{Amplification and Sequencing of the Coding Sequences of Msh Barley Genes}

The exon sequences of five Msh genes in cpm and the control were obtained by Sanger sequencing the copy DNA from embryo RNA. Primers (see Table S1) were designed with Primer3 
software (ELIXIR-European research infrastructure for biological information, University of Tartu, Tartu, Estonia; https://primer3.ut.ee/ (accessed on 21 August 2021)) using the most probable structural annotation of barley Msh genes. Moreover, the $5^{\prime} \mathrm{UTR}$ region of the Msh1 gene was amplified using three different forward primers: E1F1 and EIF2 ( $5^{\prime}-$ GCCCCGACATTTCCCAAAAC- $3^{\prime}$ and $5^{\prime}$-GAGAGGCCGCAAAACCCTAG- ${ }^{\prime}$ ) in combination with E11R (5'-GCCTCCCTTCCAACGAGATAG-3') and E1F3 (5'-CGACTCAATCCT CCGGCG-3') in combination with E10R (5'-GAACCATCAAACCAGTCAAAGGA-3'). The amplification of a single band each of the sizes expected for these amplicons was determined by RT-PCR before sequencing. For the RT-PCR, approximately 100-200 mg of embryos was collected from seeds grown for $48 \mathrm{~h}$ with an $8 \mathrm{~h}$ photoperiod, flash frozen with liquid nitrogen and processed using Trizol (Invitrogen, Waltham, MA, USA) for total RNA isolation without DNase digestion. RNA concentrations were measured using a spectrophotometer (Nanodrop, Thermo Scientific, Wilmington, DE, USA). cDNA was synthesized with Superscript III reverse transcriptase using random primers and $1 \mu \mathrm{g}$ of RNA, according to the manufacturer's instructions (Invitrogen, Waltham, MA, USA). PCRs for amplifying the cDNA were performed using $2 \mu \mathrm{L}$ of cDNA, $1 \times$ Taq buffer, $1.25 \mathrm{mM}$ $\mathrm{MgCl}_{2}, 0.6 \mu \mathrm{M}$ of each primer, $0.6 \mathrm{mM}$ of deoxynucleotide triphosphate (dNTP) mix and 1.25 units kit T-plus $5 \mathrm{U} / \mu \mathrm{L}$ Taq DNA polymerase (Inbio Highway, Tandil, Argentina). After denaturation at $94{ }^{\circ} \mathrm{C}$ for $3 \mathrm{~min}$, the reaction mixtures were heated to $94{ }^{\circ} \mathrm{C}$ for $30 \mathrm{~s}$, $60{ }^{\circ} \mathrm{C}$ for $1 \mathrm{~min}$, and $72{ }^{\circ} \mathrm{C}$ for $2 \mathrm{~min}$ in 35 cycles and $10 \mathrm{~min}$ at $72{ }^{\circ} \mathrm{C}$.

\subsection{Analyses of DNA Sequences of cpm, Control and CLs Seedlings}

A genomic DNA region corresponding to the $M s h 1$ gene was amplified and sequenced in cpm, control and several CLs. Genomic DNA was isolated from 1 or 2 leaves of individual seedlings using the micro method described in [61] with modifications. The tissue was ground with Dellaporta isolation buffer in the The Fast Prep ${ }^{\circledR}$-24 Instrument (MP Biomedicals, Santa Ana, CA, USA) and extracted with chloroform before DNA precipitation. DNA concentrations were measured using a spectrophotometer (NanoDrop, Thermo Fisher Scientific, Wilmington, DE, USA) and standardized to a concentration of $80 \mathrm{ng} / \mu \mathrm{L}$. A PCR reaction was performed in a final volume of $12.5 \mu \mathrm{L}$ using $40 \mathrm{ng}$ of genomic DNA, $1 \times$ Taq buffer $(50 \mathrm{mM} \mathrm{KCl}, 10 \mathrm{mM}$ Tris- $\mathrm{HCl}, \mathrm{pH} 9.0,0.1 \%$ Triton X100), $1.25 \mathrm{mM} \mathrm{MgCl}_{2}, 0.6 \mu \mathrm{M}$ of each primer, $0.6 \mathrm{mM}$ dNTP mix and 1.25 units kit T-plus $5 \mathrm{U} / \mu \mathrm{L}$ Taq DNA polymerase (Inbio Highway, Tandil, Argentina). After denaturation at $94{ }^{\circ} \mathrm{C}$ for $3 \mathrm{~min}$, the reaction mixtures were heated to $94{ }^{\circ} \mathrm{C}$ for $30 \mathrm{~s}, 60{ }^{\circ} \mathrm{C}$ for $1 \mathrm{~min}$ and $72{ }^{\circ} \mathrm{C}$ for $1 \mathrm{~min}$ in 35 cycles and $10 \mathrm{~min}$ at $72{ }^{\circ} \mathrm{C}$. A $655 \mathrm{bp}$ fragment was amplified using primers Hvmsh1_914F 5'-ACCAGGCAATATCTTCATCGGA-3' and Hvmsh1_914R 5'-ACСАTTCTTCCCCAACCCTTC-3'.

\subsection{Alignments and Polymorphism Identification}

cDNA, DNA and protein sequences of cpm, control and CLs were aligned with Clustal O 1.2.4 Software (EMBL-EBI, Cambridge, United Kingdom) and Vector NTI 10.0. Software (Life Technologies, Carlsbad, CA, USA) for polymorphisms identification. Assembly and graphics were done with Vector NTI 10.0. software.

Supplementary Materials: The following are available online at https: / www.mdpi.com/article / $10.3390 / \mathrm{ijms} 23031814 / \mathrm{s} 1$.

Author Contributions: Conceptualization, F.L. and A.R.P.; methodology, F.L. and A.L.; investigation, F.L. and A.R.P.; writing-original draft preparation, F.L., A.L. and A.R.P.; writing-review and editing, F.L., A.L. and A.R.P.; project administration, A.L. All authors have read and agreed to the published version of the manuscript.

Funding: This research was funded by INTA (Instituto Nacional de Tecnología Agropecuaria), PNBIO-1131024; PE I115-001 and by INTEA, DEC 21829451.

Institutional Review Board Statement: Not applicable. 
Informed Consent Statement: Not applicable.

Data Availability Statement: The Msh CDS sequences of the analyzed genes in cpm and the control were deposited in the Genbank database: cpm Msh1 (Genbank accession no. MZ747162), control Msh1 (Genbank accession no. MZ747163), cpm Msh2 (Genbank accession no. MZ747164), control Msh2 (Genbank accession no. MZ747165), cpm Msh3 (Genbank accession no. MZ747166), control Msh3 (Genbank accession no. MZ747167), cpm Msh6 (Genbank accession no. MZ747168), control Msh6 (Genbank accession no. MZ747169), cpm Msh7 (Genbank accession no. MZ747170) and control Msh7 (Genbank accession no. MZ747171).

Acknowledgments: We are very grateful to Barbara Hohn for encouraging us to submit the manuscript and for the invaluable suggestions that greatly improved the original version. We would also like to thank Abel Mario Moglie and José Cuello for their skillful handling of the plant material. In memory of Ewald A. Favret (1921-1992), a pioneer in the use of induced mutations in research and crop breeding who contributed early on, with novel results about the effects of chemical mutagens and their interactions with $X$-rays, the relationship between the different effects of mutagenic treatments and the use of wheat and barley mutants to elucidate the genetic basis of the hormonal control of growth, the grain protein content and plant disease reactions.

Conflicts of Interest: The authors declare no conflict of interest.

\section{References}

1. Morley, S.A.; Ahmad, N.; Nielsen, B.L. Plant Organelle Genome Replication. Plants 2019, 8, 358. [CrossRef] [PubMed]

2. Wu, Z.; Waneka, G.; Broz, A.K.; King, C.R.; Sloan, D.B. MSH1 Is Required for Maintenance of the Low Mutation Rates in Plant Mitochondrial and Plastid Genomes. Proc. Natl. Acad. Sci. USA 2020, 117, 16448-16455. [CrossRef] [PubMed]

3. Chevigny, N.; Schatz-Daas, D.; Lotfi, F.; Gualberto, J.M. DNA Repair and the Stability of the Plant Mitochondrial Genome. Int. J. Mol. Sci. 2020, 21, 328. [CrossRef] [PubMed]

4. Ahmad, N.; Nielsen, B.L. Plant Organelle DNA Maintenance. Plants 2020, 9, 683. [CrossRef] [PubMed]

5. Palmer, J.D. Comparative Organization of Chloroplast Genomes. Annu. Rev. Genet. 1985, 19, 325-354. [CrossRef] [PubMed]

6. Palmer, J.D. Contrasting Modes and Tempos of Genome Evolution in Land Plant Organelles. Trends Genet. 1990, 6, 115-120. [CrossRef]

7. Wolfe, K.H.; Li, W.H.; Sharp, P.M. Rates of Nucleotide Substitution Vary Greatly among Plant Mitochondrial, Chloroplast, and Nuclear DNAs. Proc. Natl. Acad. Sci. USA 1987, 84, 9054-9058. [CrossRef]

8. Clegg, M.T. Chloroplast Gene Sequences and the Study of Plant Evolution. Proc. Natl. Acad. Sci. USA 1993, 90, 363-367. [CrossRef]

9. Wicke, S.; Schneeweiss, G.M.; de Pamphilis, C.W.; Müller, K.F.; Quandt, D. The Evolution of the Plastid Chromosome in Land Plants: Gene Content, Gene Order, Gene Function. Plant Mol. Biol. 2011, 76, 273-297. [CrossRef]

10. Zhang, J.; Ruhlman, T.A.; Sabir, J.S.M.; Blazier, J.C.; Weng, M.-L.; Park, S.; Jansen, R.K. Coevolution between Nuclear-Encoded DNA Replication, Recombination, and Repair Genes and Plastid Genome Complexity. Genome Biol. Evol. 2016, 8, 622-634. [CrossRef]

11. Kirk, J.T.; Tilney-Bassett, R.A. The Plastids: Their Chemistry, Structure, Growth and Inheritance; Elsevier/North: Amsterdam, The Netherland, 1978.

12. Börner, T.; Sears, B. Plastome mutants. Plant Mol. Biol. Rep. 1986, 4, 69-72. [CrossRef]

13. Gressel, J.; Levy, A.A. Stress, Mutators, Mutations and Stress Resistance. In Abiotic Stress Adaptation in Plants: Physiological, Molecular and Genomic Foundation; Pareek, A., Sopory, S.K., Bohnert, H.J., Eds.; Springer: Dordrecht, The Netherlands, 2010; pp. 471-483, ISBN 978-90-481-3112-9.

14. Greiner, S. Plastome mutants of higher plants. In Genomics of Chloroplasts and Mitochondria; Advances in Photosynthesis and Respiration 35 Including Bioenergy and Related Processes; Bock, R., Knoop, V., Eds.; Springer: Dordrecht, The Netherlands, 2012; pp. 237-266, ISBN 978-94-007-2919-3.

15. Prina, A.R.; Pacheco, M.G.; Landau, A.M. Mutation Induction in Cytoplasmic Genomes. In Plant Mutation Breeding and Biotechnology; Shu, Q.S., Forster, B.P., Nakagawa, H., Eds.; FAO-IAEA: Rome, Italy, 2012; pp. 201-206.

16. Prina, A.R.; Landau, A.; Colombo, N.; Jaureguialzo, M.; Arias, M.C.; Rios, R.D.; Pacheco, M.G. Genetically Unstable Mutants as Novel Sources of Genetic Variability: The Chloroplast Mutator Genotype in Barley as a Tool for Exploring the Plastid Genome. In Induced Plant Mutations in the Genomics Era; Shu, Q.Y., Ed.; FAO-IAEA: Rome, Italy, 2009; pp. 255-256.

17. Prina, A.R. A Mutator Nuclear Gene Inducing a Wide Spectrum of Cytoplasmically Inherited Chlorophyll Deficiencies in Barley. Theoret. Appl. Genet. 1992, 85, 245-251. [CrossRef] [PubMed]

18. Prina, A.R. Mutator-Induced Cytoplasmic Mutants in Barley: Genetic Evidence of Activation of a Putative Chloroplast Transposon. J. Hered. 1996, 87, 385-389. [CrossRef]

19. Landau, A.M.; Pacheco, M.G.; Prina, A.R. A Second InfA Plastid Gene Point Mutation Shows a Compensatory Effect on the Expression of the Cytoplasmic Line 2 (CL2) Syndrome in Barley. J. Hered. 2011, 102, 633-639. [CrossRef] [PubMed] 
20. Landau, A.; Díaz Paleo, A.; Civitillo, R.; Jaureguialzo, M.; Prina, A.R. Two InfA Gene Mutations Independently Originated from a Mutator Genotype in Barley. J. Hered. 2007, 98, 272-276. [CrossRef] [PubMed]

21. Landau, A.M.; Lokstein, H.; Scheller, H.V.; Lainez, V.; Maldonado, S.; Prina, A.R. A Cytoplasmically Inherited Barley Mutant Is Defective in Photosystem I Assembly Due to a Temperature-Sensitive Defect in Ycf3 Splicing. Plant Physiol. 2009, 151, 1802-1811. [CrossRef]

22. Rios, R.D.; Saione, H.; Robredo, C.; Acevedo, A.; Colombo, N.; Prina, A.R. Isolation and Molecular Characterization of Atrazine Tolerant Barley Mutants. Theor. Appl. Genet. 2003, 106, 696-702. [CrossRef]

23. Landau, A.; Lencina, F.; Pacheco, M.G.; Prina, A.R. Plastome Mutations and Recombination Events in Barley Chloroplast Mutator Seedlings. J. Hered. 2016, 107, 266-273. [CrossRef]

24. Lencina, F.; Landau, A.M.; Petterson, M.E.; Pacheco, M.G.; Kobayashi, K.; Prina, A.R. The Rpl23 Gene and Pseudogene Are Hotspots of Illegitimate Recombination in Barley Chloroplast Mutator Seedlings. Sci. Rep. 2019, 9, 9960. [CrossRef]

25. Lencina, F.; Landau, A.M.; Pacheco, M.G.; Kobayashi, K.; Prina, A.R. Four Large Indels Detected by CpTILLING in Barley Chloroplast Mutator Seedlings I BioRxiv. Available online: https://www.biorxiv.org/content/10.1101/2021.02.19.432034v1 (accessed on 17 August 2021).

26. Spampinato, C.P.; Gomez, R.L.; Galles, C.; Lario, L.D. From Bacteria to Plants: A Compendium of Mismatch Repair Assays. Mutat. Res. 2009, 682, 110-128. [CrossRef]

27. Manova, V.; Gruszka, D. DNA Damage and Repair in Plants-from Models to Crops. Front. Plant Sci. 2015, 6, 885. [CrossRef] [PubMed]

28. Harfe, B.D.; Jinks-Robertson, S. DNA Mismatch Repair and Genetic Instability. Annu. Rev. Genet. 2000, 34, 359-399. [CrossRef] [PubMed]

29. Jun, S.-H.; Kim, T.G.; Ban, C. DNA Mismatch Repair System. Classical and Fresh Roles. FEBS J. 2006, 273, 1609-1619. [CrossRef] [PubMed]

30. Lin, Z.; Nei, M.; Ma, H. The Origins and Early Evolution of DNA Mismatch Repair Genes—Multiple Horizontal Gene Transfers and Co-Evolution. Nucleic Acids Res. 2007, 35, 7591-7603. [CrossRef]

31. Fukui, K.; Harada, A.; Wakamatsu, T.; Minobe, A.; Ohshita, K.; Ashiuchi, M.; Yano, T. The GIY-YIG Endonuclease Domain of Arabidopsis MutS Homolog 1 Specifically Binds to Branched DNA Structures. FEBS Lett. 2018, 592, 4066-4077. [CrossRef]

32. Bray, C.M.; West, C.E. DNA Repair Mechanisms in Plants: Crucial Sensors and Effectors for the Maintenance of Genome Integrity. New Phytol. 2005, 168, 511-528. [CrossRef]

33. Culligan, K.M.; Hays, J.B. Arabidopsis MutS Homologs-AtMSH2, AtMSH3, AtMSH6, and a Novel AtMSH7-Form Three Distinct Protein Heterodimers with Different Specificities for Mismatched DNA. Plant Cell 2000, 12, 991-1002. [CrossRef]

34. Eisen, J. A Phylogenomic Study of the MutS Family of Proteins. Nucleic Acids Res. 1998, 26, 4291-4300. [CrossRef]

35. Snowden, T.; Acharya, S.; Butz, C.; Berardini, M.; Fishel, R. HMSH4-HMSH5 Recognizes Holliday Junctions and Forms a Meiosis-Specific Sliding Clamp That Embraces Homologous Chromosomes. Mol. Cell 2004, 15, 437-451. [CrossRef]

36. Abdelnoor, R.V.; Yule, R.; Elo, A.; Christensen, A.C.; Meyer-Gauen, G.; Mackenzie, S.A. Substoichiometric Shifting in the Plant Mitochondrial Genome Is Influenced by a Gene Homologous to MutS. Proc. Natl. Acad. Sci. USA 2003, 100, 5968-5973. [CrossRef]

37. Shedge, V.; Arrieta-Montiel, M.; Christensen, A.C.; Mackenzie, S.A. Plant Mitochondrial Recombination Surveillance Requires Unusual RecA and MutS Homologs. Plant Cell 2007, 19, 1251-1264. [CrossRef]

38. Arrieta-Montiel, M.P.; Shedge, V.; Davila, J.; Christensen, A.C.; Mackenzie, S.A. Diversity of the Arabidopsis Mitochondrial Genome Occurs via Nuclear-Controlled Recombination Activity. Genetics 2009, 183, 1261-1268. [CrossRef] [PubMed]

39. Boesch, P.; Weber-Lotfi, F.; Ibrahim, N.; Tarasenko, V.; Cosset, A.; Paulus, F.; Lightowlers, R.N.; Dietrich, A. DNA Repair in Organelles: Pathways, Organization, Regulation, Relevance in Disease and Aging. Biochim. Biophys. Acta 2011, 1813, 186-200. [CrossRef]

40. Odahara, M.; Kishita, Y.; Sekine, Y. MSH1 Maintains Organelle Genome Stability and Genetically Interacts with RECA and RECG in the Moss Physcomitrella Patens. Plant J. 2017, 91, 455-465. [CrossRef]

41. Wu, S.-Y.; Culligan, K.; Lamers, M.; Hays, J. Dissimilar Mispair-Recognition Spectra of Arabidopsis DNA-Mismatch-Repair Proteins MSH2·MSH6 (MutS $\alpha$ ) and MSH2·MSH7 (MutS $\gamma$ ). Nucleic Acids Res. 2003, 31, 6027-6034. [CrossRef]

42. Hoffman, P.D.; Leonard, J.M.; Lindberg, G.E.; Bollmann, S.R.; Hays, J.B. Rapid Accumulation of Mutations during Seed-to-Seed Propagation of Mismatch-Repair-Defective Arabidopsis. Genes Dev. 2004, 18, 2676-2685. [CrossRef]

43. Emmanuel, E.; Yehuda, E.; Melamed-Bessudo, C.; Avivi-Ragolsky, N.; Levy, A.A. The Role of AtMSH2 in Homologous Recombination in Arabidopsis Thaliana. EMBO Rep. 2006, 7, 100-105. [CrossRef]

44. Jiang, M.; Wu, X.; Song, Y.; Shen, H.; Cui, H. Effects of OsMSH6 Mutations on Microsatellite Stability and Homeologous Recombination in Rice. Front. Plant Sci. 2020, 11, 220. [CrossRef]

45. Rayssiguier, C.; Thaler, D.S.; Radman, M. The Barrier to Recombination between Escherichia Coli and Salmonella Typhimurium Is Disrupted in Mismatch-Repair Mutants. Nature 1989, 342, 396-401. [CrossRef]

46. Abdelnoor, R.V.; Christensen, A.C.; Mohammed, S.; Munoz-Castillo, B.; Moriyama, H.; Mackenzie, S.A. Mitochondrial Genome Dynamics in Plants and Animals: Convergent Gene Fusions of a MutS Homologue. J. Mol. Evol. 2006, 63, 165-173. [CrossRef]

47. Maréchal, A.; Brisson, N. Recombination and the Maintenance of Plant Organelle Genome Stability. New Phytol. 2010, 186, $299-317$. [CrossRef] 
48. Redei, G.P. Extrachromosomal mutability determined by a nuclear gene locus in Arabidopsis. Mutat Res. 1973, 18, 149-162. [CrossRef]

49. Martínez-Zapater, J.M.; Gil, P.; Capel, J.; Somerville, C.R. Mutations at the Arabidopsis CHM Locus Promote Rearrangements of the Mitochondrial Genome. Plant Cell 1992, 4, 889-899.

50. Sakamoto, W.; Kondo, H.; Murata, M.; Motoyoshi, F. Altered Mitochondrial Gene Expression in a Maternal Distorted Leaf Mutant of Arabidopsis Induced by Chloroplast Mutator. Plant Cell 1996, 8, 1377-1390. [CrossRef] [PubMed]

51. Xu, Y.Z.; Arrieta-Montiel, M.P.; Virdi, K.S.; de Paula, W.B.M.; Widhalm, J.R.; Basset, G.J.; Davila, J.I.; Elthon, T.E.; Elowsky, C.G.; Sato, S.J.; et al. Muts Homolog1 Is a Nucleoid Protein That Alters Mitochondrial and Plastid Properties and Plant Response to High Light. Plant Cell 2011, 23, 3428-3441. [CrossRef] [PubMed]

52. Christensen, A.C.; Lyznik, A.; Mohammed, S.; Elowsky, C.G.; Elo, A.; Yule, R.; Mackenzie, S.A. Dual-Domain, Dual-Targeting Organellar Protein Presequences in Arabidopsis Can Use Non-AUG Start Codons. Plant Cell 2005, 17, 2805-2816. [CrossRef] [PubMed]

53. Xu, Y.-Z.; Santamaria, R.D.L.R.; Virdi, K.S.; Arrieta-Montiel, M.P.; Razvi, F.; Li, S.; Ren, G.; Yu, B.; Alexander, D.; Guo, L.; et al. The Chloroplast Triggers Developmental Reprogramming When MutS HOMOLOG1 Is Suppressed in Plants. Plant Physiol. 2012, 159, 710-720. [CrossRef]

54. Virdi, K.S.; Laurie, J.D.; Xu, Y.Z.; Yu, J.; Shao, M.R.; Sanchez, R.; Kundariya, H.; Wang, D.; Riethoven, J.J.M.; Wamboldt, Y.; et al. Arabidopsis MSH1 Mutation Alters the Epigenome and Produces Heritable Changes in Plant Growth. Nat. Commun. 2015, 6, 6386. [CrossRef]

55. Virdi, K.S.S.; Wamboldt, Y.; Kundariya, H.; Laurie, J.D.D.; Keren, I.; Kumar, K.R.S.; Block, A.; Basset, G.; Luebker, S.; Elowsky, C.; et al. MSH1 Is a Plant Organellar DNA Binding and Thylakoid Protein under Precise Spatial Regulation to Alter Development. Mol. Plant 2016, 9, 245-260. [CrossRef]

56. Shao, M.R.; Kumar Kenchanmane Raju, S.; Laurie, J.D.; Sanchez, R.; Mackenzie, S.A. Stress-Responsive Pathways and Small RNA Changes Distinguish Variable Developmental Phenotypes Caused by MSH1 Loss. BMC Plant Biol. 2017, 17, 47. [CrossRef]

57. Beltrán, J.; Wamboldt, Y.; Sanchez, R.; LaBrant, E.W.; Kundariya, H.; Virdi, K.S.; Elowsky, C.; Mackenzie, S.A. Specialized Plastids Trigger Tissue-Specific Signaling for Systemic Stress Response in Plants. Plant Physiol. 2018, 178, 672-683. [CrossRef] [PubMed]

58. MacKenzie, S.A.; Kundariya, H. Organellar Protein Multi-Functionality and Phenotypic Plasticity in Plants. Philos. Trans. R. Soc. B Biol. Sci. 2019, 375. [CrossRef] [PubMed]

59. Yang, X.; Sanchez, R.; Kundariya, H.; Maher, T.; Dopp, I.; Schwegel, R.; Virdi, K.; Axtell, M.J.; Mackenzie, S.A. Segregation of an MSH1 RNAi Transgene Produces Heritable Non-Genetic Memory in Association with Methylome Reprogramming. Nat. Commun. 2020, 11, 2214. [CrossRef] [PubMed]

60. Prina, A.R.; Arias, M.C.; Lainez, V.; Landau, A.; Maldonado, S. A Cytoplasmically Inherited Mutant Controlling Early Chloroplast Development in Barley Seedlings. Theor. Appl. Genet. 2003, 107, 1410-1418. [CrossRef] [PubMed]

61. Dellaporta, S. Plant DNA Miniprep and Microprep: Versions 2.1-2.3. In The Maize Handbook; Springer Lab Manuals; Freeling, M., Walbot, V., Eds.; Springer: New York, NY, USA, 1994; pp. 522-525, ISBN 978-1-4612-2694-9. 